\title{
23 LOOKING BACK AND LOOKING FORWARD: Diffusion and Adoption of Information Technology Research in IFIP WG 8.6-Achievements and Future Challenges
}

\author{
Karlheinz Kautz \\ Copenhagen Business School \\ Copenhagen, Denmark \\ Robert W. Zmud \\ University of Oklahoma \\ Norman, OK U.S.A. \\ Gonzalo Leon Serrano \\ Technical University of Madrid \\ Madrid, Spain \\ Eleanor H. Wynn \\ Intel Corporation \\ Hillsboro, OR U.S.A. \\ Tor J. Larsen \\ Norwegian School of Management \\ Sandvika, Norway \\ E. Burton Swanson \\ University and California, Los Angeles \\ Los Angeles, CA U.S.A.
}

Working Group 8.6 has existed for more than 10 years now. During this period, members have continuously challenged the work of the group. Recently, researchers at the Copenhagen Business Schcol conducted an interim review of the group's work in the form of a literature analysis of all WG 8.6 conference contributions. That review concludes that WG 8.6 works 
toward and within its own aim and scope declaration, but that there are a number of challenges. One is that WG 8.6 has no joint terminology and no shared theoretical basis. One recommendation from the review team, therefore, was that beyond researching new technologies like mobile information system and management fashions and fads such as business agility, WG 8.6 should stay with its roots and do work to explicitly contribute to IT diffusion theory and terminology. On the basis of this interim review, a group of founding, regular, less-regular, and more-recent members of WG 8.6 take a brief look back and a more extended look forward to discuss the achievements and the future challenges of WG 8.6 .

The participants of the panel will provide their positions in 10-15 minutes statements.

Robert W. Zmud, Michael F. Price College of Business, University of Oklahoma, is a founding member of WG 8.6 and has contributed to the group's work in various ways. His position comprises a request to broaden the field of diffusion and adoption research to include the adoption, diffusion, and transfer of entities (information, knowledge, business practices, best practices, etc.) that are associated with IT and to place more emphasis on end-stage outcomes (e.g., de-adoption, infusion, institutionalization).

Gonzalo Leon Serrano, Department of Telematic Systems Engineering, Technical University of Madrid, is a founding member of WG 8.6, but has not been an active participant in the group's work for several years. From his recent experience as an adviser for the Spanish government, he discusses the way that governments and the European Commission are addressing the technology transfer and diffusion issue and its consequences. His request is to integrate these issues into the group's work.

Eleanor H. Wynn, IT Innovation at Intel Corporation, recently jointed WG 8.6 and organized one of its conferences. She sees a future challenge in extending the concept of diffusion and adoption into the area of complex systems and social network dynamics. Based on her work on adaptive systems modeling of distributed servers and distributed engineers in an IT service organization, she discusses the challenge of embedding innovation diffusion in a sociotechnical network of software engineers into the group's work.

Tor J. Larsen, Department of Leadership and Organizational Management, Norwegian School of Management, is a founding member of WG 8.6 and has organized two of the group's conferences, as well as participating in nearly all others. He is occupied with the fundamental issue of terms employed by the group and what they might mean. Thus, he brings forward the demand to work harder on answering the question of what diffusion actually means. In this context, he argues for comparing the group's concepts with others such as advertising, marketing, and consultancy.

E. Burton Swanson, Anderson School of Management, UCLA, is a founding member of WG 8.6 and has participated in a number of its conferences. His starting point arises directly from the interim review, literally taking the challenges presented and providing ideas of how WG 8.6 can overcome its apparent shortcomings.

Karlheinz Kautz, Department of Informatics, Copenhagen Business School, is a founding member of WG 8.6 and has participated in all of the group's conferences. As one of the authors of the interim review of the group's work, which is included in this volume, he will briefly introduce that document and otherwise act as facilitator. 